\title{
PD-L1 expression is associated with ALK positivity and STAT3 activation, but not outcome in patients with systemic anaplastic large cell lymphoma
}

\author{
Jing Shen ${ }^{1,2} \cdot$ Shaoying Li $\mathbb{D}^{1} \cdot$ L. Jeffrey Medeiros ${ }^{1} \cdot$ Pei Lin $^{1} \cdot$ Sa A. Wang ${ }^{1} \cdot$ Guilin Tang ${ }^{1} \cdot$ C. Cameron Yin ${ }^{1}$ \\ M. James You ${ }^{1} \cdot$ Joseph D. Khoury $\mathbb{D}^{1} \cdot$ Swaminathan P. Iyer ${ }^{3} \cdot$ Roberto N. Miranda $\mathbb{D}^{1} \cdot$ Jie Xu $\mathbb{D}^{1}$
}

Received: 30 April 2019 / Revised: 3 July 2019 / Accepted: 4 July 2019 / Published online: 5 August 2019

(c) United States \& Canadian Academy of Pathology 2019

\begin{abstract}
The programmed cell death 1 (PD-1) pathway is a recently recognized mechanism of tumor immune evasion. In this study, programmed cell death ligand 1 (PD-L1) expression was evaluated in 95 patients with systemic anaplastic large cell lymphoma: $45 \mathrm{ALK}+$ and $50 \mathrm{ALK}-$. ALK + anaplastic large cell lymphoma was more often positive for PD-L1 than ALK - anaplastic large cell lymphoma ( $76 \%$ vs $42 \%, p=0.002)$. ALK - anaplastic large cell lymphoma showed a strong correlation between PD-L1 expression and STAT3 activation (measured by pSTAT3 $\left.{ }^{\mathrm{Ty} 705}\right)(r=0.8, p<0.0001)$. In contrast, the PD-L1/pSTAT3 correlation was weaker in ALK + anaplastic large cell lymphoma $(r=0.4, p=0.08)$. In ALKanaplastic large cell lymphoma, the PD-L1+ subgroup was more often EMA positive $(69 \%$ vs $20 \%, p=0.02)$ and tended to be less often CD2+ $(50 \%$ vs $83 \%, p=0.059)$. In ALK + anaplastic large cell lymphoma, PD-L1 was not associated with pathologic features (all $p>0.05$ ). Negative ALK status and high IPI score $(\geq 3)$ were associated with shorter overall survival $(p=0.009$ and $p=0.0005$, respectively). Overall survival was not different between patients with PD-L1+ vs PD-L1anaplastic large cell lymphoma $(p=0.44)$, regardless of ALK status and International Prognostic Index (IPI) score. We conclude that PD-L1 expression is more common in ALK + anaplastic large cell lymphoma than ALK - anaplastic large cell lymphoma. In ALK - anaplastic large cell lymphoma, PD-L1 is strongly correlated with STAT3 activation and is associated with more frequent EMA and less frequent CD2 expression. PD-L1 has no prognostic significance in predicting the outcome of patients with systemic anaplastic large cell lymphoma, regardless of ALK status. PD-L1 expression on the anaplastic large cell lymphoma cells suggests these patients as potential candidates for PD-1 blockade immunotherapy.
\end{abstract}

\section{Introduction}

Systemic anaplastic large cell lymphoma is a CD30+ T-cell lymphoma usually composed of large pleomorphic cells with horseshoe-shaped nuclei and abundant cytoplasm. These neoplasms can be further classified into ALK+ and ALK - types [1]. ALK + anaplastic large cell lymphoma is

Jie Xu

jxu9@mdanderson.org

1 Department of Hematopathology, The University of Texas MD Anderson Cancer Center, Houston, TX, USA

2 Department of Hematology, Capital Medical University Beijing Friendship Hospital, Beijing, China

3 Department of Lymphoma and Myeloma, The University of Texas MD Anderson Cancer Center, Houston, TX, USA characterized by ALK protein expression resulting from translocations involving $A L K$ at $2 \mathrm{p} 23$, most commonly $\mathrm{t}$ $(2 ; 5)(\mathrm{p} 23 ; \mathrm{q} 35) / N P M 1-A L K$. Compared to ALK + anaplastic large cell lymphoma, patients with ALK - anaplastic large cell lymphoma are usually older and have more aggressive clinical course and a poorer outcome. The long-term overall survival rates are 70-90\% in patients with ALK+ anaplastic large cell lymphoma but $<50 \%$ in patients with ALKanaplastic large cell lymphoma [2-11].

Programmed cell death ligand 1 (PD-L1, also known as CD274 or B7-H1) is normally expressed by antigenpresenting cells. After PD-L1 binds to its receptor, programmed cell death 1 (PD-1) on the effector T cells, PD-L1 inhibits $\mathrm{T}$-cell receptor signaling and proliferation ( $\mathrm{T}$ cell "exhaustion"). A subset of malignant tumors including some types of lymphoma expresses PD-L1 to escape T-cellmediated killing, conferring an adverse prognosis [12-23]. A few small studies have reported PD-L1 expression in 
Table 1 Clinical features of patients with PD-L1+ and PDL1 - anaplastic large cell lymphoma

\begin{tabular}{|c|c|c|c|c|c|c|}
\hline & \multicolumn{3}{|c|}{$\mathrm{ALK}+\mathrm{ALCL}(n=45)$} & \multicolumn{3}{|c|}{$\operatorname{ALK}-\operatorname{ALCL}(n=50)$} \\
\hline & $\begin{array}{l}\text { PD-L1+ } \\
(n=34)\end{array}$ & $\begin{array}{l}\text { PD-L1- } \\
(n=11)\end{array}$ & $P$ value $^{\mathrm{b}}$ & $\begin{array}{l}\text { PD-L1+ } \\
(n=21)\end{array}$ & $\begin{array}{l}\text { PD-L1- } \\
(n=29)\end{array}$ & $P$ value \\
\hline Male:female & $1.3: 1(19 / 15)$ & $2.7: 1(8 / 3)$ & 0.48 & $3.2: 1(16 / 5)$ & $2.2: 1(20 / 9)$ & 0.75 \\
\hline $\begin{array}{l}\text { Median age } \\
\text { (yrs, range) }\end{array}$ & $36(11-58)$ & $29(11-67)$ & 0.61 & $64(43-95)$ & $58(21-77)$ & 0.09 \\
\hline B symptoms & $59 \%(13 / 22)$ & $44 \%(4 / 9)$ & 0.69 & $69 \%(11 / 16)$ & $57 \%(12 / 21)$ & 0.52 \\
\hline Nodal presentation & $79 \%(23 / 29)$ & $89 \%(8 / 9)$ & 1 & $72 \%(13 / 18)$ & $74 \%(20 / 27)$ & 1 \\
\hline $\begin{array}{l}\text { Extranodal } \\
\text { involvement }\end{array}$ & $68 \%(19 / 28)$ & $36 \%(4 / 11)$ & 0.14 & $78 \%(14 / 18)$ & $65 \%(15 / 23)$ & 0.5 \\
\hline $\begin{array}{l}\text { Bone marrow } \\
\text { involvement }\end{array}$ & $21 \%(5 / 24)$ & $0 \%(0 / 10)$ & 0.29 & $22 \%(4 / 18)$ & $17 \%(4 / 23)$ & 0.71 \\
\hline Stage III or IV & $75 \%(18 / 24)$ & $50 \%(5 / 10)$ & 0.23 & $56 \%(9 / 16)$ & $81 \%(17 / 21)$ & 0.15 \\
\hline Elevated WBC & $28 \%(5 / 18)$ & $25 \%(1 / 4)$ & 1 & $45 \%(5 / 11)$ & $14 \%(2 / 14)$ & 0.18 \\
\hline $\begin{array}{l}\text { Absolute } \\
\text { lymphocytosis }\end{array}$ & $0 \%(0 / 17)$ & $0 \%(0 / 3)$ & 1 & $0 \%(0 / 11)$ & $0 \%(0 / 13)$ & 1 \\
\hline $\begin{array}{l}\text { Elevated } \\
\text { serum LDH }\end{array}$ & $50 \%(9 / 18)$ & $50 \%(2 / 4)$ & 1 & $60 \%(6 / 10)$ & $67 \%(8 / 12)$ & 1 \\
\hline $\mathrm{IPI} \geq 3$ & $17 \%(3 / 18)$ & $13 \%(1 / 8)$ & 1 & $53 \%(8 / 15)$ & $44 \%(7 / 16)$ & 0.72 \\
\hline \multicolumn{7}{|l|}{ Initial treatment } \\
\hline $\begin{array}{c}\text { CHOP or } \\
\text { modified CHOP }\end{array}$ & $71 \%(17 / 24)$ & $80 \%(8 / 10)$ & 0.69 & $86 \%(12 / 14)$ & $83 \%(19 / 23)$ & 1 \\
\hline Other & $29 \%(7 / 24)$ & $20 \%(2 / 10)$ & & $14 \%(2 / 14)$ & $17 \%(4 / 23)$ & \\
\hline Initial CR & $79 \%(19 / 24)$ & $90 \%(9 / 10)$ & 0.64 & $29 \%(4 / 14)$ & $61 \%(14 / 23)$ & 0.09 \\
\hline With SCT & $29 \%(7 / 24)$ & $60 \%(6 / 10)$ & 0.13 & $14 \%(2 / 14)$ & $26 \%(6 / 23)$ & 0.68 \\
\hline
\end{tabular}

$A L C L$ anaplastic large cell lymphoma, $W B C$ white blood cells, $L D H$ lactate dehydrogenase, IPI International Prognostic Index, CHOP cyclophosphamide, doxorubicin, vincristine, and prednisone, $R$ rituximab, $C R$ complete response, $S C T$ stem cell transplant

${ }^{\mathrm{a}} \geq 5 \%$ of lymphoma cells were positive for PD-L1

${ }^{\mathrm{b}} \mathrm{ALK}+/ \mathrm{PD}-\mathrm{L} 1+$ ALCL compared with ALK+/PD-L1 - ALCL

${ }^{\mathrm{c}} \mathrm{ALK}-/ \mathrm{PD}-\mathrm{L} 1+$ ALCL compared with ALK-/PD-L1 - ALCL
ALK + and ALK - anaplastic large cell lymphoma, including cell lines and patient tissue specimens [19, 24-26]. In ALK + and ALK - anaplastic large cell lymphoma cell lines, PD-L1 expression was regulated by STAT3 activation; knocking down STAT3 by siRNA constructs resulted in significantly decreased PD-L1 protein levels [24, 25].

In this study, we assessed PD-L1 in 95 patients with systemic anaplastic large cell lymphoma. We correlated PDL1 expression with clinicopathologic features, ALK status and STAT3 activation, and we assessed the potential impact of PD-L1 expression on the outcome of patients with systemic anaplastic large cell lymphoma.

\section{Materials and methods}

\section{Case selection}

We searched the database of the Department of Hematopathology at The University of Texas MD Anderson Cancer
Center from January 1, 2007 to December 31, 2018 for cases of systemic anaplastic large cell lymphoma that had material available for immunohistochemistry. The diagnosis and sub-classification of anaplastic large cell lymphoma were based on the criteria specified in the 2016 World Health Organization classification [1]. The diagnosis of ALK + anaplastic large cell lymphoma was confirmed by ALK expression by immunohistochemistry and/or $\mathrm{t}(2 ; 5)$ (p23;q35) by conventional cytogenetics or $A L K$ rearrangement by fluorescence in situ hybridization (FISH) analysis. Clinical information was obtained by review of medical records. This study was approved by the institutional review board.

\section{Immunophenotypic analysis}

Immunohistochemical studies were performed using formalin-fixed, paraffin-embedded tissue sections, either at the time of diagnosis or retrospectively for this study as described previously [27]. Immunohistochemical analysis 
was performed on an automated immunostainer (Leica Bond-Max IHC Stainer, San Diego, CA). The 4- $\mu$ m-thick tissue sections were deparaffinized and underwent heatinduced antigen retrieval using the Bond Max Epitope Retrieval 1 solution for $15 \mathrm{~min}$. The antibodies used were specific for CD2, CD7, EMA (Leica Biosystems, Newcastle, United Kingdom); CD3, CD20, CD43, CD45, and Ki67 (Dako, Carpinteria, CA, USA); CD4 (Cell Marque, Rocklin, CA, USA); CD5 (SP4; Labvision/Neomarkers, Fremont, CA, USA); CD8, granzyme B (Thermo Fisher, Waltham, MA, USA); ALK, phospho-STAT3 (Tyr705) (Cell Signaling, Danvers, MA, USA); PAX5 (Transduction Labs, San Diego, CA, USA); PD-L1 (Dako, Santa Clara, CA, USA). The positive cutoff value for PD-L1 was $\geq 5 \%$ $[14,15]$. The Bond Refine Polymer detection system was used for visualization.

Flow cytometry immunophenotypic analysis was performed on cell suspensions of tissue biopsy specimens or bone marrow aspirates using either a FACScanto II or FACSCalibur cytometer (Becton-Dickinson Biosciences, San Jose, CA, USA) as has been described [27]. Lymphocytes were gated for analysis using side scatter vs forward scatter and CD45 expression vs side scatter. The panel of monoclonal antibodies included reagents specific for $\mathrm{CD} 2, \mathrm{CD} 3, \mathrm{CD} 4, \mathrm{CD} 5, \mathrm{CD} 7$, CD8, CD10, CD25, CD30, CD45, TCR-AB, TCR-GD (Becton-Dickinson Biosciences, San Jose, CA, USA).

\section{Conventional cytogenetic analysis and fluorescence in situ hybridization}

Conventional cytogenetic analysis was performed on metaphase cells prepared from bone marrow aspirates or cell suspensions from tissue biopsy specimens as described previously [28]. Twenty Giemsa-banded metaphases were analyzed, and the results were reported using the 2016 International System for Human Cytogenetic Nomenclature. FISH analysis was performed using a LSI ALK dual color, breakapart rearrangement probe on interphase nuclei obtained from bone marrow cells or tissue sections, according to the manufacturer's instructions (Abbott Molecular, Des Plaines, IL, USA).

\section{Statistical analysis}

Statistical analyses were performed using the Graph-Pad Prism 7. Fisher's exact test was utilized to compare the clinicopathologic features between PD-L1+ vs PD-L1subgroups in patients with ALK + or ALK - anaplastic large cell lymphoma. Overall survival was calculated from the date of initial diagnosis to the date of death or last follow-up. Survival was analyzed using the Kaplan-Meier method and was compared using the log rank test. A $p$-value of less than 0.05 was considered statistically significant.

\section{Results}

\section{Clinical findings}

We identified 95 cases of anaplastic large cell lymphoma that had PD-L1 results assessed: 45 ALK+ and 50 ALK-. The clinical features of these patients are summarized in Table 1. The ALK + anaplastic large cell lymphoma cases included 34 (76\%) that were PD-L1+ and 11 that were PDL1-. The ALK+/PD-L1+ subgroup included 19 men and 15 women with a median age of 36 years (range, 11-58 years) at the time of diagnosis. Thirteen of $22(59 \%)$ patients had B symptoms. Lymphadenopathy was identified in 23 of $29(79 \%)$ patients and 19 of $28(68 \%)$ had extranodal involvement. Bone marrow was involved in 5 of 24 (21\%) patients assessed. Eighteen of $24(75 \%)$ fully staged patients had stage III or IV disease. Five of $18(28 \%)$ patients had an elevated white blood cell count. No patients had absolute lymphocytosis. Nine of $18(50 \%)$ patients tested showed an elevated serum LDH level. The International Prognostic Index (IPI) [29] was available for 18 patients: $15(83 \%)$ patients had a low or intermediate IPI score $(0,1$, or 2$)$ whereas three $(17 \%)$ patients had a high IPI score $(3,4$, or 5). The ALK+/PD-L1 - subgroup included 11 patients, eight men and three women with a median age of 29 years (11-67). Four of nine (44\%) had B symptoms, eight of nine (89\%) had lymphadenopathy, and four of $11(36 \%)$ had extranodal disease. Bone marrow was not involved and half of these patients had stage III or IV disease. These features were very similar to the ALK+/PDL1+subgroup (all $p>0.05$; Table 1).

The ALK - anaplastic large cell lymphoma cases included 21 (42\%) positive for PD-L1 and 29 negative for PDL1. As shown in Table 1, there were no significant differences in the clinical features between the PD-L1+ vs PD-L1 - subgroups of ALK - anaplastic large cell lymphoma (all $p>0.05$ ).

\section{Pathologic findings}

PD-L1 expression, assessed by immunohistochemistry, showed a membranous staining pattern; a small subset of lymphoma cells in some cases had a membranous and paranuclear dot-like or Golgi staining pattern (Fig. 1f). In 30 of $45(67 \%)$ cases of ALK + anaplastic large cell lymphoma, $\geq 20 \%$ of lymphoma cells were positive for PD-L1 (Table 2). In contrast, in 29 of $50(58 \%)$ cases of ALKanaplastic large cell lymphoma, $<5 \%$ of lymphoma cells were positive for PD-L1. Using $\geq 5 \%$ as the cutoff value, the PD-L1 positivity rate in ALK + anaplastic large cell lymphoma was higher than that in ALK - anaplastic large cell lymphoma ( $76 \%$ vs $42 \%, p=0.002$; Table 3 ). On average, $42 \%$ of lymphoma cells in ALK+ anaplastic large cell 


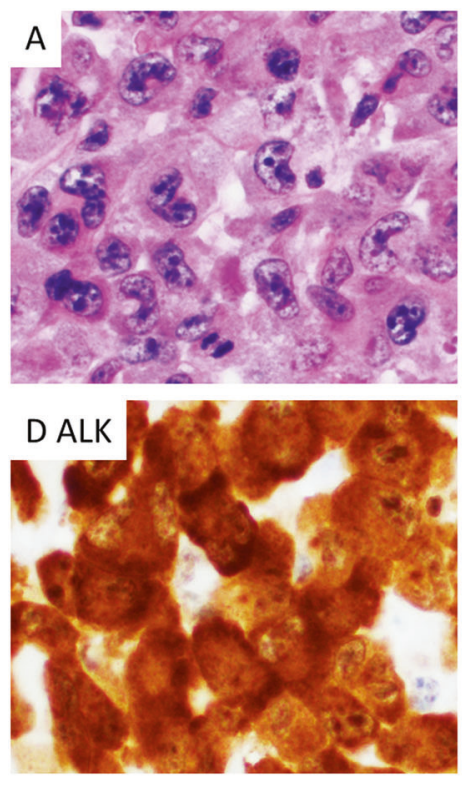

Fig. 1 An ALK + anaplastic large cell lymphoma case with strong PDL1 expression. The lymphoma cells were large, with pleomorphic, often horseshoe- or kidney-shaped nuclei and abundant cytoplasm (a, hematoxylin and eosin stain, $\times 400)$. The lymphoma cells showed uniform, strong CD30 positivity on the cell membrane and in the Golgi region (b, immunohistochemistry, $\times 400)$, loss of CD3 expression $(\mathbf{c}$, immunohistochemistry, $\times 400)$, nuclear and cytoplasmic staining for ALK (d, immunohistochemistry, $\times 400)$, and granzyme B positivity (e, immunohistochemistry, $\times 400$ ). The lymphoma cells were positive for PD-L1, mainly membranous staining, with a small subset of cells showing Golgi staining pattern (f, immunohistochemistry, $\times 400$ )

lymphoma were positive for PD-L1, significantly higher than the mean of $20 \%$ positive cells in the ALK - anaplastic large cell lymphoma (Fig. 2, $p=0.0006$ ).

Activation of STAT3 was also analyzed, determined by assessing for nuclear expression of phosphorylated STAT3 $\left(\right.$ pSTAT3 $\left.^{\text {Tyr705 }}\right)$. A mean of $53 \%$ lymphoma cells in ALK+ anaplastic large cell lymphoma showed nuclear staining of pSTAT3, higher than the mean of $27 \%$ observed in ALKanaplastic large cell lymphoma (Fig. 3a, $p=0.007$ ). A weak correlation was found between PD-L1 expression and pSTAT3 in ALK + anaplastic large cell lymphoma (Fig. 3b, $r=0.4, p=0.08$ ). In contrast, there was a strong correlation between PD-L1 expression and pSTAT3 in ALK - anaplastic large cell lymphoma (Fig. 3c, $r=0.8, p<0.0001$; Fig. 3d-i).

In the patients with ALK+ anaplastic large cell lymphoma, PD-L1 + cases included 29 (85\%) with common (or classic) morphologic features, $3(5 \%)$ with small-cell

Table 2 Percentage of PD-L1+ lymphoma cells in anaplastic large cell lymphoma

\begin{tabular}{lllll}
\hline & \multicolumn{4}{l}{ PD-L1 lymphoma cells } \\
\cline { 2 - 5 } & $<5 \%$ & $5-9 \%$ & $10-19 \%$ & $\geq 20 \%$ \\
\hline ALK+ ALCL $(n=45)$ & $11(24 \%)$ & $1(2 \%)$ & $3(7 \%)$ & $30(67 \%)$ \\
ALK- ALCL $(n=50)$ & $29(58 \%)$ & $1(2 \%)$ & $3(6 \%)$ & $17(34 \%)$ \\
\hline
\end{tabular}

$A L C L$ anaplastic large cell lymphoma morphology, and 2 (4\%) with lymphohistiocytic morphology (Table 4). No significant difference in morphologic patterns were found between the PD-L1+ vs PD-L1subgroups of ALK + anaplastic large cell lymphoma $(p=$ 0.38). Twenty-eight cases were assessed by flow cytometry and immunohistochemistry. There was no significant difference in pan T-cell antigen loss comparing these two techniques $(p>0.05$; data not shown). No cases were assessed only by flow cytometry. Combining flow cytometry and immunohistochemical findings (Table 4), the ALK+/PD-L1+anaplastic large cell lymphoma subgroup showed variable expression of T-cell antigens: nine of 24 (38\%) were positive for CD2, seven of 31 (23\%) were positive for CD3, 17 of 25 (68\%) were positive for CD4, 10 of $24(42 \%)$ were positive for CD5, three of 13 (23\%) were positive for $\mathrm{CD} 7$, and one (5\%) case was positive for CD8. All ALK+/PD-L1+ anaplastic large cell lymphoma cases were positive for $\mathrm{CD} 25$ and most of them were positive for EMA (16/17; 94\%), granzyme B (8/10; 80\%), CD45 (17/ $25 ; 68 \%)$, and CD43 (11/17; 65\%). There was no significant difference in the pathological features between the PD-L1+ vs PD-L1 - subgroups of ALK+ anaplastic large cell lymphoma (all $p>0.05$; Table 4 ).

In the patients with ALK - anaplastic large cell lymphoma, the morphologic and immunophenotypic features of PD-L1+ vs PD-L1 - subgroups were also compared and most of the features were similar between these two subgroups except for EMA and CD2. PD-L1+ cases were more 
Table 3 High PD-L1 positivity rate in ALK+ anaplastic large cell lymphoma

\begin{tabular}{lllll}
\hline & No. of case & PD-L1+(n[\%]) & PD-L1-negative $(n[\%])$ & $P$-value \\
\hline ALK + ALCL & 45 & $34(76 \%)$ & $11(24 \%)$ & 0.002 \\
ALK - ALCL & 50 & $21(42 \%)$ & $29(58 \%)$ & \\
\hline
\end{tabular}

$A L C L$ anaplastic large cell lymphoma

${ }^{a} \geq 5 \%$ of lymphoma cells were positive for PD-L1

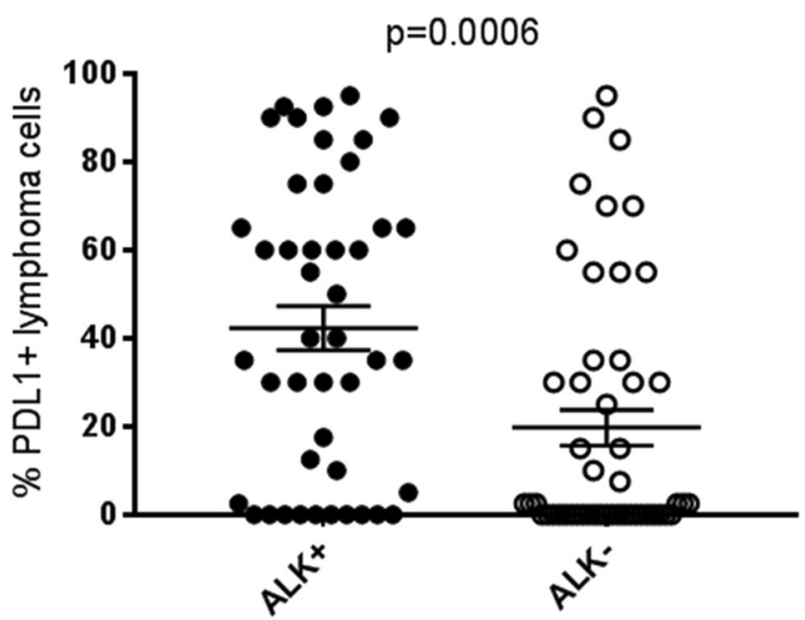

Fig. 2 PD-L1 expression in anaplastic large cell lymphoma was associated with ALK positivity. The percentage of PD-L1+ lymphoma cells in anaplastic large cell lymphoma was higher than that in ALKnegative anaplastic large cell lymphoma

often positive for EMA than PD-L1 - cases $(69 \%$ vs $20 \%$, $p=0.02)$. PD-L1 + cases were less likely to express CD2 compared with the PD-L1 - subgroup, although this result was marginally significant ( $p=0.059$; Table 4$)$.

\section{Treatment and response}

Thirty-four patients with ALK+ anaplastic large cell lymphoma and 37 patients with ALK - anaplastic large cell lymphoma had treatment information available. All of these patients were treated with different chemotherapy regimens over the time interval of this study, with or without stem cell transplant. In the patients with PD-L1+ ALK+ anaplastic large cell lymphoma, 17 (71\%) were treated with cyclophosphamide, doxorubicin, vincristine, and prednisone (CHOP) or modified CHOP (Table 1). After initial induction chemotherapy, 19 of 24 (79\%) patients with PD-L1+ ALK + anaplastic large cell lymphoma achieved complete remission and seven (29\%) patients received autologous stem cell transplant. In the patients with PD-L1 - ALK+ anaplastic large cell lymphoma, eight $(80 \%)$ were treated with $\mathrm{CHOP}$ or modified CHOP. After initial induction chemotherapy, nine of 10 (90\%) patients with PD-L1ALK + anaplastic large cell lymphoma achieved complete remission and six (60\%) patients received stem cell transplant: four autologous, one allogeneic, one autologous followed by allogeneic.

There was no significant difference in treatment or initial complete remission rate between the PD-L1+ vs PD-L1subgroups in patients with either ALK + or ALK - anaplastic large cell lymphoma (all $p>0.05$; Table 1).

\section{Outcome}

After a median clinical follow-up of 20.3 months (range, 0-224 months), 27 of 77 (35\%) patients died. Negative ALK and high IPI score were associated with shorter overall survival ( $p=0.009$ and $p=0.0005$, respectively) (Fig. 4a, b). The median overall survival of patients with PD-L1+ anaplastic large cell lymphoma was 20.8 months, not significantly different from patients with PD-L1 - anaplastic large cell lymphoma ( $p=0.44$, Fig. $4 c)$. Since ALK and IPI status were major prognostic factors in anaplastic large cell lymphoma, survival analysis were further performed in patients based on the status of these two factors. PD-L1 expression did not affect overall survival in anaplastic large cell lymphoma patients regardless of ALK status or IPI score (all $p>0.05$, Fig. 5a-d).

\section{Discussion}

In the literature, most studies of PD-L1 in lymphomas have been focused on B-cell lymphomas. PD-L1 expression is commonly positive in the neoplastic cells of classic Hodgkin lymphoma, primary mediastinal large B-cell lymphoma, T-cell/histiocyte-rich large B-cell lymphoma, and EBV+ diffuse large B-cell lymphoma [14, 19, 20]. The particularly high expression rate of PD-L1 in classic Hodgkin lymphoma plays a role in these neoplasms being sensitive to PD-1 blockade therapy. In patients with relapsed or refractory Hodgkin lymphoma, PD-1-blocking antibodies led to an overall response rate of $65-87 \%$ (16-17\% with complete response, $48-70 \%$ with partial response) and a $24-$ week progression-free survival rate of $69-86 \%[30,31]$. Amplification of chromosome 9p24.1/PD-L1/PD-L2 or PDL1 expression was associated with poorer prognosis in patients with classic Hodgkin lymphoma [20, 32]. Although only a small subset (11-24\%) of cases of diffuse large Bcell lymphoma show PD-L1 expression [14, 19], PD-L1 

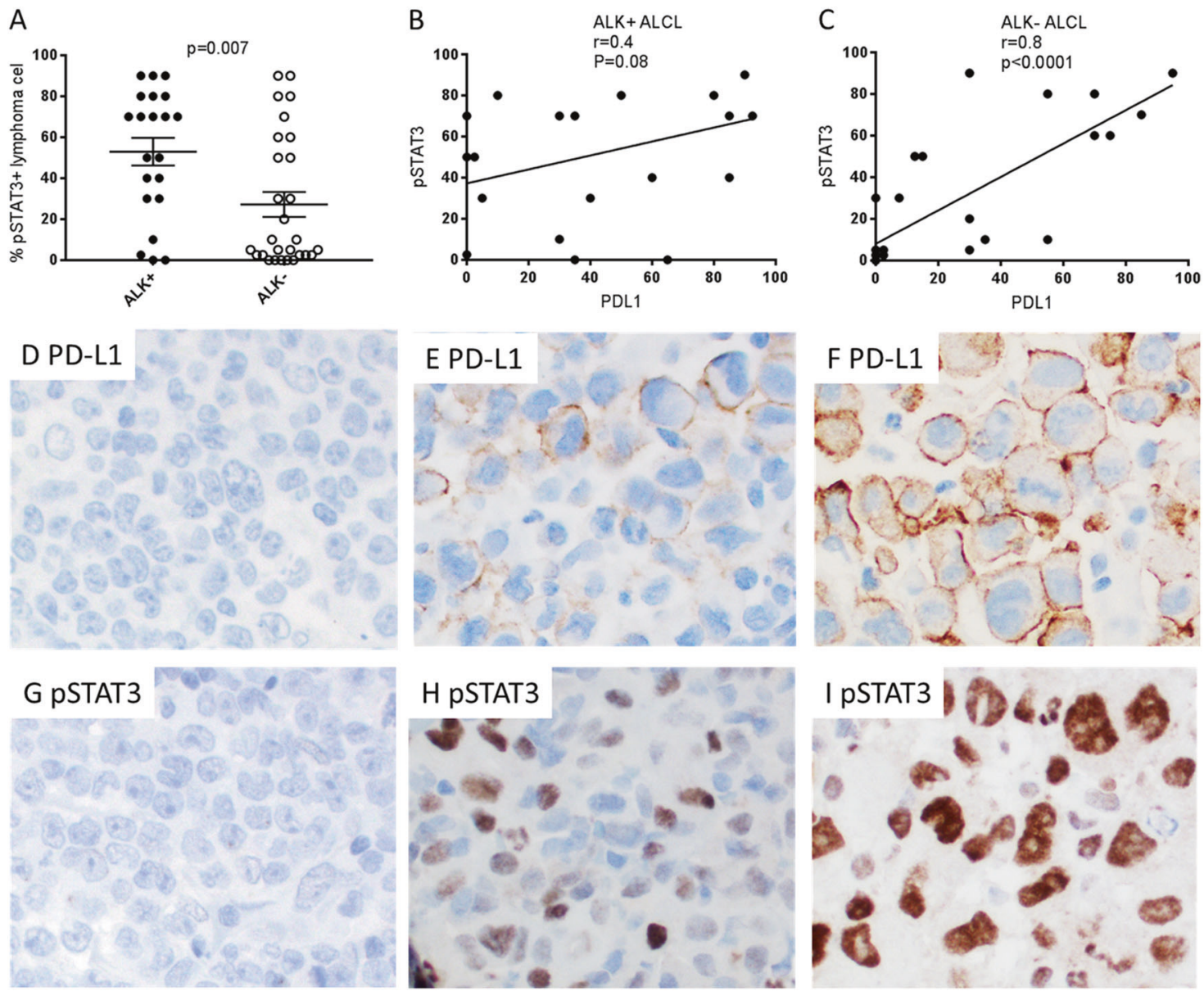

Fig. 3 Correlation between PD-L1 expression and pSTAT3 in anaplastic large cell lymphoma. a The percentage of pSTAT3+ lymphoma cells in ALK+ anaplastic large cell lymphoma was higher than that in ALK-negative anaplastic large cell lymphoma. $\mathbf{b}, \mathbf{c}$, The percentage of PD-L1+ lymphoma cells was correlated with the percentage of
pSTAT3 + lymphoma cells, weakly $(\mathbf{b}, r=0.4)$ in ALK + but strongly (c, $r=0.8)$ in ALK-negative anaplastic large cell lymphoma. $\mathbf{d}-\mathbf{i}$ representative pictures showing the correlation between PD-L1 and pSTAT3 (d-f PD-L1 immunohistochemistry, $\times 400 ; \mathbf{g}-\mathbf{i}$, pSTAT3 immunohistochemistry, $\times 400)$ expression in diffuse large B-cell lymphoma is associated with non-germinal center B-cell subtype [19, 21, 23, 33]. Most studies of diffuse large B-cell lymphoma have reported an association between PD-L1 expression and shorter overall survival [21-23], but in other studies PD-L1 expression has not been associated with prognostic impact [33].

Two small studies have shown strong expression of PDL1 in ALK + anaplastic large cell lymphoma cell lines and patient specimens [19, 24]. A recent study reported that 12 of $15(80 \%)$ anaplastic large cell lymphomas (ALK+ and ALL - together) were positive for PD-L1 [26]. A relatively larger study reported PD-L1 expression in 18 of $36(50 \%)$ ALK + anaplastic large cell lymphoma and 18 of 24 (67\%) of ALK - anaplastic large cell lymphoma [25]. In this large study, we detected PD-L1 expression in about three quarters of ALK+ anaplastic large cell lymphoma cases and about $40 \%$ of ALK - anaplastic large cell lymphoma cases. We also show that PD-L1 expression in anaplastic large cell lymphoma is associated with ALK positivity in patient specimens.

It has been reported in anaplastic large cell lymphoma cell lines that NPM1-ALK fusion protein induces PD-L1 expression through the activation of STAT3 [24]. In ALK+ anaplastic large cell lymphoma, the oncogenic effect of ALK fusion protein was mostly mediated by STAT3, which was required for cell transformation and tumor maintenance [34, 35]. Knocking down STAT3 by siRNA constructs resulted in decreased PD-L1 protein levels in anaplastic large cell lymphoma cells [24, 25]. The constitutive activation of the JAK/STAT signaling pathway is a central pathogenic feature of ALK+ as well as ALK - anaplastic large cell lymphoma. Activating mutations of JAKl and/or STAT3 have been shown in $20 \%$ of the ALK - anaplastic large cell lymphoma cases; recurrent chimeras combining a transcription factor (NFkB2 or NCOR2) with a tyrosine kinase (ROS1 or TYK2) were discovered in $22 \%$ of ALK - anaplastic large cell lymphoma, all in the absence of 
Table 4 Pathological features of patients with PD-L1+ and PDL1 - anaplastic large cell lymphoma

\begin{tabular}{|c|c|c|c|c|c|c|}
\hline & \multicolumn{3}{|c|}{$\mathrm{ALK}+\mathrm{ALCL}(n=45)$} & \multicolumn{3}{|c|}{ ALK $-\operatorname{ALCL}(n=50)$} \\
\hline & $\begin{array}{l}\text { PD-L1+ }{ }^{\mathrm{a}} \\
(n=34)\end{array}$ & $\begin{array}{l}\text { PD-L1- } \\
(n=11)^{\mathrm{a}}\end{array}$ & $P$-value ${ }^{\mathrm{b}}$ & $\begin{array}{l}\text { PD-L1+ }{ }^{\mathrm{a}} \\
(n=21)\end{array}$ & $\begin{array}{l}\text { PD-L1- } \\
(n=29)\end{array}$ & $P$-value ${ }^{\mathrm{c}}$ \\
\hline \multicolumn{7}{|l|}{ Morphologic type } \\
\hline Common pattern & $85 \%(29 / 34)$ & $73 \%(8 / 11)$ & 0.38 & $100 \%(21 / 21)$ & $97 \%(28 / 29)$ & 1 \\
\hline $\begin{array}{l}\text { Non-common } \\
\text { pattern }\end{array}$ & $14 \%(5 / 34)$ & $27 \%(3 / 11)$ & & $0 \%(0 / 21)$ & $3 \%(1 / 29)$ & \\
\hline \multicolumn{7}{|l|}{ Immunophenotype } \\
\hline $\mathrm{CD} 2+$ & $38 \%(9 / 24)$ & $71 \%(5 / 7)$ & 0.2 & $50 \%(6 / 12)$ & $83 \%(19 / 23)$ & 0.059 \\
\hline $\mathrm{CD} 3+$ & $23 \%(7 / 31)$ & $45 \%(5 / 11)$ & 0.24 & $38 \%(8 / 21)$ & $63 \%(17 / 27)$ & 0.14 \\
\hline $\mathrm{CD} 4+$ & $68 \%(17 / 25)$ & $33 \%(2 / 6)$ & 0.17 & $89 \%(17 / 19)$ & $81 \%(21 / 26)$ & 0.68 \\
\hline $\mathrm{CD} 5+$ & $42 \%(10 / 24)$ & $43 \%(3 / 7)$ & 1 & $40 \%(6 / 15)$ & $58 \%(14 / 24)$ & 0.33 \\
\hline $\mathrm{CD} 7+$ & $23 \%(3 / 13)$ & $33 \%(1 / 3)$ & 1 & $27 \%(3 / 11)$ & $37 \%(7 / 19)$ & 0.7 \\
\hline $\mathrm{CD} 8+$ & $5 \%(1 / 19)$ & $17 \%(1 / 6)$ & 0.43 & $0 \%(0 / 14)$ & $13 \%(3 / 24)$ & 0.28 \\
\hline $\mathrm{CD} 25+$ & $100 \%(9 / 9)$ & $67 \%(2 / 3)$ & 0.25 & $100 \%(2 / 2)$ & $60 \%(3 / 5)$ & 1 \\
\hline $\mathrm{CD} 43+$ & $65 \%(11 / 17)$ & $100 \%(5 / 5)$ & 0.27 & $70 \%(7 / 10)$ & $100 \%(9 / 9)$ & 0.21 \\
\hline $\mathrm{CD} 45+$ & $68 \%(17 / 25)$ & $75 \%(3 / 4)$ & 1 & $73 \%(11 / 15)$ & $92 \%(12 / 13)$ & 0.33 \\
\hline Granzyme B+ & $80 \%(8 / 10)$ & $100 \%(4 / 4)$ & 1 & $56 \%(5 / 9)$ & $33 \%(2 / 6)$ & 0.61 \\
\hline EMA+ & $94 \%(16 / 17)$ & $100 \%(5 / 5)$ & 1 & $69 \%(9 / 13)$ & $20 \%(3 / 15)$ & 0.02 \\
\hline
\end{tabular}

$A L C L$ anaplastic large cell lymphoma

${ }^{a} \geq 5 \%$ of lymphoma cells were positive for PD-L1

${ }^{\mathrm{b}} \mathrm{ALK}+/ \mathrm{PD}-\mathrm{L} 1+$ ALCL compared with ALK + /PD-L1 - ALCL

${ }^{\mathrm{c}} \mathrm{ALK}-/ \mathrm{PD}-\mathrm{L} 1+$ ALCL compared with ALK-/PD-L1 - ALCL
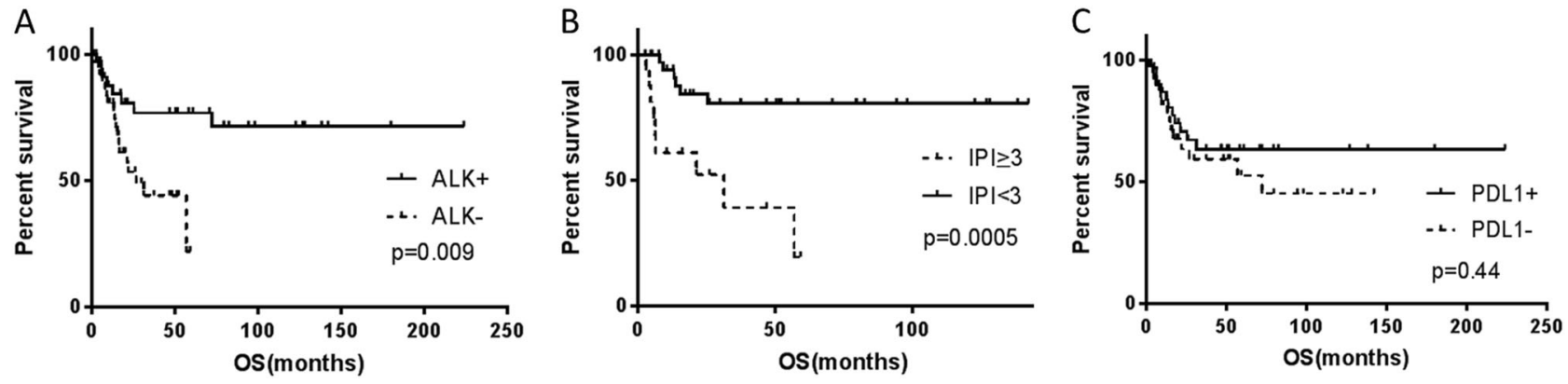

Fig. 4 The impact of ALK status, International Prognostic Index (IPI) score, and PD-L1 expression on overall survival of patients with anaplastic large cell lymphoma. Negative ALK status (a) and

JAK1 or STAT3 mutation [36]. All these aberrations lead to the constitutive activation of the JAK/STAT pathway. Nuclear pSTAT3 expression was seen in almost $85 \%$ of ALK + anaplastic large cell lymphoma cases and nearly half of ALK - anaplastic large cell lymphoma cases in a previous study [37]. Similarly, we found that pSTAT3 was associated with ALK activity. We also found that PD-L1 expression correlated with pSTAT3, particularly strong in ALK - anaplastic large cell lymphoma, suggesting that PDL1 expression in anaplastic large cell lymphoma is likely regulated by STAT3 activation. According to the World Health Organization classification 2016, ALK + and ALKanaplastic large cell lymphomas are considered as two high IPI score (b), but not PD-L1 (c), were associated with shorter overall survival

separate entities with distinct genetic profiles. In addition to STAT3, some other unknown factors or pathways may also regulate PD-L1 expression in ALK + anaplastic large cell lymphoma, which may explain the weaker PD-L1/ pSTAT3 correlation observed in ALK + anaplastic large cell lymphoma.

Most cases of anaplastic large cell lymphoma have a cytotoxic T-cell immunophenotype and do not express one or more T-cell antigens $[1,3,10]$. For example, CD3, CD5, and $\mathrm{T}$-cell receptors are commonly absent in anaplastic large cell lymphoma. It is also true that cases of ALK+ and ALK - anaplastic large cell lymphoma often show differences in their immunophenotype. CD3 and CD5 are more 
Fig. 5 PD-L1 had no prognostic significance in patients with anaplastic large cell lymphoma, regardless of ALK status and International Prognostic Index (IPI) score. $\mathbf{a}$ in patients with ALK+ anaplastic large cell lymphoma. $\mathbf{b}$ in patients with ALK - anaplastic large cell lymphoma. $\mathbf{c}$ in patients with low IPI score $(<3)$. $\mathbf{d}$ in patients with high IPI score $(\geq 3)$
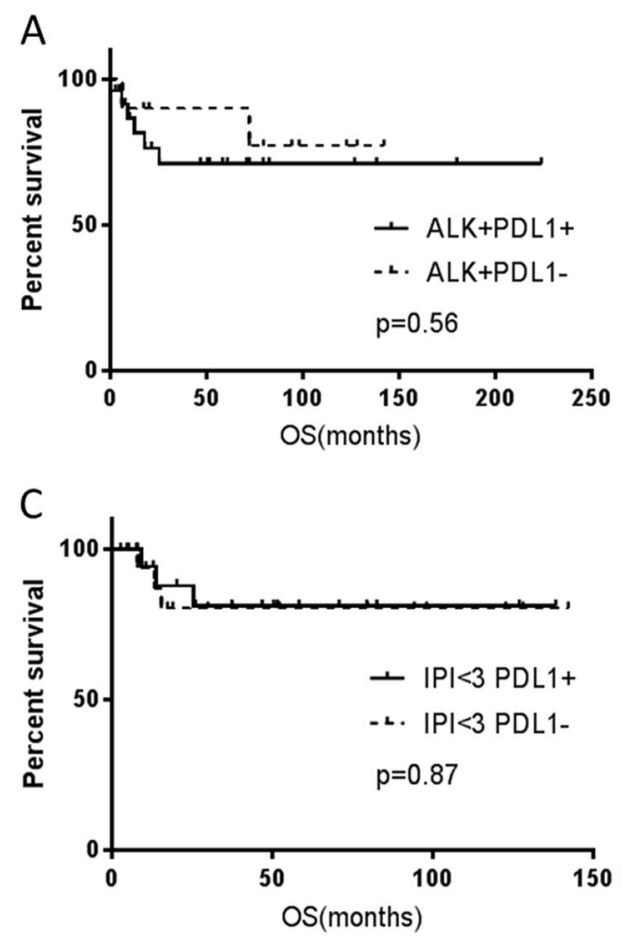
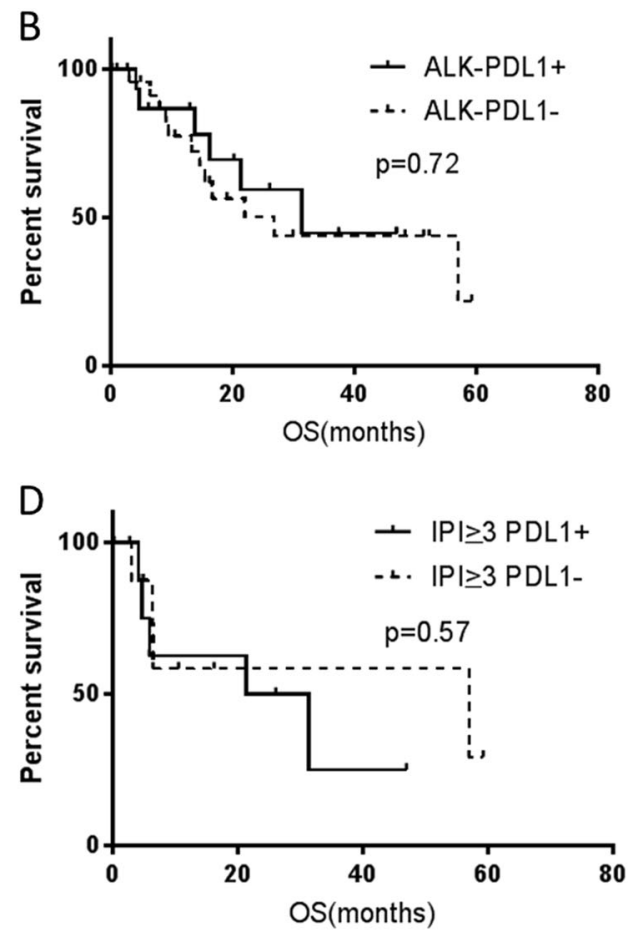

often negative in ALK + anaplastic large cell lymphoma $[3,7,8]$. About $80 \%$ of ALK+ anaplastic large cell lymphoma cases are positive for EMA, compared with $43 \%$ of ALK - cases [3]. ALK+ anaplastic large cell lymphoma cases are usually negative for Bcl-2 whereas at least half of ALK - anaplastic large cell lymphoma cases are positive [38]. The results of the current study add to these differences as we found that PD-L1 expression is far more common in ALK+ anaplastic large cell lymphoma.

Patients with ALK+ anaplastic large cell lymphoma generally have a better prognosis than patients with ALKanaplastic large cell lymphoma with 5-year overall survival rates of $70-90 \%$ vs $<50 \%$, respectively $[2-5,8,11]$. In this study, ALK expression was significantly associated with longer overall survival. The International Prognostic Index (IPI), a clinical risk stratification model initially developed for aggressive non-Hodgkin lymphomas [29], is also effective in stratifying patients with anaplastic large cell lymphoma [3-6, 8, 11]. Although ALK+ anaplastic large cell lymphoma is generally associated with a good prognosis, ALK + anaplastic large cell lymphoma patients with an IPI score of $\geq 3$ had a 5-year overall survival of only $20-30 \%$, similar to that of patients with other types of peripheral T-cell lymphoma; conversely, ALK - anaplastic large cell lymphoma patients with a low IPI score had a favorable prognosis [3]. Our data confirm that high risk IPI score $(\geq 3)$ was associated with poorer outcome (shorter overall survival). Although there were small series reports about PD-L1 expression in anaplastic large cell lymphoma in the literature, none have studied its prognostic significance in anaplastic large cell lymphoma. Our data show that PD-L1 expression is not associated with overall survival in anaplastic large cell lymphoma, regardless of ALK status and IPI score. In other words, despite its association with ALK, PD-L1 had no prognostic significance in this cohort of anaplastic large cell lymphoma patients. In some studies, ALK expression has not been identified as an independent prognostic factor in multivariate analysis, mainly because of the correlation between younger age and ALK positivity. If the analysis was limited to patients younger than 40 years old, patients with ALKanaplastic large cell lymphoma have good outcomes similar to those with ALK+ anaplastic large cell lymphoma, suggesting that age might be a major factor driving the difference in outcomes [7]. In the current study, there was no significant difference in age between patients with PD-L1+ vs PD-L1 - anaplastic large cell lymphoma, which might explain the lack of impact of PD-L1 on patient outcome.

Although many innovative drugs including aggressive chemotherapy and targeted agents, such as anti-CD30 antibody and ALK inhibitors, have been developed to treat patients with systemic anaplastic large cell lymphoma [39], the clinical outcome of patients with ALK - or refractory/relapsed ALK+ anaplastic large cell lymphoma is still poor, with 5-year overall survival rate of $<50 \%$ [40, 41]. PD-L1 expression on anaplastic large cell lymphoma cells provides a strong rationale for PD-1 blockade as a potential treatment for those patients. Durable complete remission achieved by anti-PD1 antibodies (nivolumab and pembrolizumab) have been reported in three patients 
with relapsed/refractory anaplastic large cell lymphoma (2 ALK+ and 1 ALK -) who had failed multiple treatment regimens including chemotherapy, ALK inhibitor, antiCD30 antibody, with or without stem cell transplant [42-44]. Two patients had PD-L1+ tumors and one patient had unknown PD-L1 status. These reports suggest that disruption of the PD-1 pathway in anaplastic large cell lymphoma can establish therapeutically effective antitumor immunity and advocate for the development of clinical trials evaluating the efficacy of PD-1 blockade in patients with refractory/relapsed anaplastic large cell lymphoma.

In conclusion, we assessed PD-L1 expression in 95 patients with systemic anaplastic large cell lymphoma and compared the clinicopathologic features and outcome between patients with PD-L1+ versus PD-L1 - tumors. The data we present suggest that PD-L1 is expressed in about three quarters of ALK + anaplastic large cell lymphoma and in a smaller subset of ALK - anaplastic large cell lymphoma. Therefore, patients with PD-L1+ anaplastic large cell lymphoma may be potential candidates for PD-1 blockade immunotherapy. In addition, in ALK - anaplastic large cell lymphoma, PD-L1 expression is strongly correlated with STAT3 activation. PD-L1 has no prognostic significance in predicting overall survival of patients with systemic anaplastic large cell lymphoma regardless of ALK status.

\section{Compliance with ethical standards}

Conflict of interest The authors declare that they have no conflict of interest.

Publisher's note: Springer Nature remains neutral with regard to jurisdictional claims in published maps and institutional affiliations.

\section{References}

1. Swerdlow SH, Campo E, Pileri SA, Harris NL, Stein H, Siebert R, et al. The 2016 revision of the World Health Organization classification of lymphoid neoplasms. Blood. 2016;127:2375-90.

2. Vose J, Armitage J, Weisenburger D. International TCLP. International peripheral $\mathrm{T}$-cell and natural killer/T-cell lymphoma study: pathology findings and clinical outcomes. J Clin Oncol. 2008;26:4124-30.

3. Savage KJ, Harris NL, Vose JM, Ullrich F, Jaffe ES, Connors JM, et al. ALK- anaplastic large-cell lymphoma is clinically and immunophenotypically different from both ALK + ALCL and peripheral T-cell lymphoma, not otherwise specified: report from the International Peripheral T-Cell Lymphoma Project. Blood. 2008;111:5496-504.

4. Falini B, Pileri S, Zinzani PL, Carbone A, Zagonel V, WolfPeeters C, et al. ALK+ lymphoma: clinico-pathological findings and outcome. Blood. 1999;93:2697-706.

5. Gascoyne RD, Aoun P, Wu D, Chhanabhai M, Skinnider BF, Greiner TC, et al. Prognostic significance of anaplastic lymphoma kinase (ALK) protein expression in adults with anaplastic large cell lymphoma. Blood. 1999;93:3913-21.
6. Suzuki R, Kagami Y, Takeuchi K, Kami M, Okamoto M, Ichinohasama R, et al. Prognostic significance of CD56 expression for ALK-positive and ALK-negative anaplastic large-cell lymphoma of T/null cell phenotype. Blood. 2000;96:2993-3000.

7. Sibon D, Fournier M, Briere J, Lamant L, Haioun C, Coiffier B, et al. Long-term outcome of adults with systemic anaplastic largecell lymphoma treated within the Groupe d'Etude des Lymphomes de l'Adulte trials. J Clin Oncol. 2012;30:3939-46.

8. ten Berge RL, de Bruin PC, Oudejans JJ, Ossenkoppele GJ, van der Valk P, Meijer CJ. ALK-negative anaplastic large-cell lymphoma demonstrates similar poor prognosis to peripheral T-cell lymphoma, unspecified. Histopathology. 2003;43:462-9.

9. Hsi ED, Said J, Macon WR, Rodig SJ, Ondrejka SL, Gascoyne $\mathrm{RD}$, et al. Diagnostic accuracy of a defined immunophenotypic and molecular genetic approach for peripheral T/NK-cell lymphomas. A North American PTCL study group project. Am J Surg Pathol. 2014;38:768-75.

10. Parrilla Castellar ER, Jaffe ES, Said JW, Swerdlow SH, Ketterling RP, Knudson RA, et al. ALK-negative anaplastic large cell lymphoma is a genetically heterogeneous disease with widely disparate clinical outcomes. Blood. 2014;124:1473-80.

11. Ellin F, Landstrom J, Jerkeman M, Relander T. Real-world data on prognostic factors and treatment in peripheral T-cell lymphomas: a study from the Swedish Lymphoma Registry. Blood. 2014;124:1570-7.

12. Zou W, Chen L. Inhibitory B7-family molecules in the tumour microenvironment. Nat Rev Immunol. 2008;8:467-77.

13. Dong H, Strome SE, Salomao DR, Tamura H, Hirano F, Flies DB, et al. Tumor-associated B7-H1 promotes T-cell apoptosis: a potential mechanism of immune evasion. Nat Med. 2002; 8:793-800

14. Chen BJ, Chapuy B, Ouyang J, Sun HH, Roemer MG, Xu ML, et al. PD-L1 expression is characteristic of a subset of aggressive B-cell lymphomas and virus-associated malignancies. Clin Cancer Res. 2013;19:3462-73.

15. Xu J, Sun HH, Fletcher CD, Hornick JL, Morgan EA, Freeman GJ, et al. Expression of Programmed Cell Death 1 Ligands (PDL1 and PD-L2) in Histiocytic and Dendritic Cell Disorders. Am J Surg Pathol. 2016;40:443-53.

16. Keir ME, Francisco LM, Sharpe AH. PD-1 and its ligands in Tcell immunity. Curr Opin Immunol. 2007;19:309-14.

17. Hamanishi J, Mandai M, Iwasaki M, Okazaki T, Tanaka Y, Yamaguchi K, et al. Programmed cell death 1 ligand 1 and tumorinfiltrating CD8 + T lymphocytes are prognostic factors of human ovarian cancer. Proc Natl Acad Sci USA. 2007;104:3360-5.

18. Gadiot J, Hooijkaas AI, Kaiser AD, van Tinteren H, van Boven H, Blank C. Overall survival and PD-L1 expression in metastasized malignant melanoma. Cancer. 2011;117:2192-201.

19. Andorsky DJ, Yamada RE, Said J, Pinkus GS, Betting DJ, Timmerman JM. Programmed death ligand 1 is expressed by nonhodgkin lymphomas and inhibits the activity of tumor-associated T cells. Clin Cancer Res. 2011;17:4232-44.

20. Menter T, Bodmer-Haecki A, Dirnhofer S, Tzankov A. Evaluation of the diagnostic and prognostic value of PDL1 expression in Hodgkin and B-cell lymphomas. Hum Pathol. 2016;54:17-24.

21. Kiyasu J, Miyoshi H, Hirata A, Arakawa F, Ichikawa A, Niino D, et al. Expression of programmed cell death ligand 1 is associated with poor overall survival in patients with diffuse large B-cell lymphoma. Blood. 2015;126:2193-201.

22. Li L, Sun R, Miao Y, Tran T, Adams L, Roscoe N, et al. PD-1/ PD-L1 expression and interaction by automated quantitative immunofluorescent analysis show adverse prognostic impact in patients with diffuse large B-cell lymphoma having T-cell infiltration: a study from the International DLBCL Consortium Program. Mod Pathol. 2019;32:741-54. 
23. Xing W, Dresser K, Zhang R, Evens AM, Yu H, Woda BA, et al. PD-L1 expression in EBV-negative diffuse large B-cell lymphoma: clinicopathologic features and prognostic implications. Oncotarget. 2016;7:59976-86.

24. Marzec M, Zhang Q, Goradia A, Raghunath PN, Liu X, Paessler $M$, et al. Oncogenic kinase NPM/ALK induces through STAT3 expression of immunosuppressive protein CD274 (PD-L1, B7H1). Proc Natl Acad Sci USA. 2008;105:20852-7.

25. Atsaves V, Tsesmetzis N, Chioureas D, Kis L, Leventaki V, Drakos E, et al. PD-L1 is commonly expressed and transcriptionally regulated by STAT3 and MYC in ALK-negative anaplastic large-cell lymphoma. Leukemia. 2017;31:1633-7.

26. Panjwani PK, Charu V, DeLisser M, Molina-Kirsch H, Natkunam Y, Zhao S. Programmed death-1 ligands PD-L1 and PD-L2 show distinctive and restricted patterns of expression in lymphoma subtypes. Hum Pathol. 2018;71:91-9.

27. Xu J, Medeiros LJ, Saksena A, Wang M, Zhou J, Li J, et al. CD10-positive mantle cell lymphoma: clinicopathologic and prognostic study of 30 cases. Oncotarget. 2018;9:11441-50.

28. Hu Z, Medeiros LJ, Chen Z, Chen W, Li S, Konoplev SN, et al. Mantle Cell Lymphoma With MYC Rearrangement: a Report of 17 Patients. Am J Surg Pathol. 2017;41:216-24.

29. International Non-Hodgkin's Lymphoma Prognostic Factors P. A predictive model for aggressive non-Hodgkin's lymphoma. N Engl J Med. 1993;329:987-94.

30. Ansell SM, Lesokhin AM, Borrello I, Halwani A, Scott EC, Gutierrez M, et al. PD-1 blockade with nivolumab in relapsed or refractory Hodgkin's lymphoma. N Engl J Med. 2015; 372:311-9.

31. Armand P, Shipp MA, Ribrag V, Michot JM, Zinzani PL, Kuruvilla J, et al. Programmed death-1 blockade with pembrolizumab in patients with classical Hodgkin lymphoma after brentuximab vedotin failure. J Clin Oncol. 2016;34:3733-9.

32. Roemer MG, Advani RH, Ligon AH, Natkunam Y, Redd RA, Homer H, et al. PD-L1 and PD-L2 Genetic Alterations Define Classical Hodgkin Lymphoma and Predict Outcome. J Clin Oncol. 2016;34:2690-7.

33. Kwon D, Kim S, Kim PJ, Go H, Nam SJ, Paik JH, et al. Clinicopathological analysis of programmed cell death 1 and programmed cell death ligand 1 expression in the tumour microenvironments of diffuse large B cell lymphomas. Histopathology. 2016;68:1079-89.
34. Zamo A, Chiarle R, Piva R, Howes J, Fan Y, Chilosi M, et al. Anaplastic lymphoma kinase (ALK) activates Stat3 and protects hematopoietic cells from cell death. Oncogene. 2002;21:1038-47.

35. Chiarle R, Simmons WJ, Cai H, Dhall G, Zamo A, Raz R, et al. Stat 3 is required for ALK-mediated lymphomagenesis and provides a possible therapeutic target. Nat Med. 2005;11:623-9.

36. Crescenzo R, Abate F, Lasorsa E, Tabbo F, Gaudiano M, Chiesa $\mathrm{N}$, et al. Convergent mutations and kinase fusions lead to oncogenic STAT3 activation in anaplastic large cell lymphoma. Cancer Cell. 2015;27:516-32.

37. Khoury JD, Medeiros LJ, Rassidakis GZ, Yared MA, Tsioli P, Leventaki V, et al. Differential expression and clinical significance of tyrosine-phosphorylated STAT3 in ALK+ and ALK- anaplastic large cell lymphoma. Clin Cancer Res. 2003;9:3692-9.

38. Rassidakis GZ, Sarris AH, Herling M, Ford RJ, Cabanillas F, McDonnell TJ, et al. Differential expression of BCL-2 family proteins in ALK-positive and ALK-negative anaplastic large cell lymphoma of T/null-cell lineage. Am J Pathol. 2001;159:527-35.

39. Prokoph N, Larose H, Lim MS, Burke GAA, Turner SD. Treatment options for paediatric anaplastic large cell lymphoma (ALCL): current standard and beyond. Cancers (Basel) 2018;10. pii: E99. https://doi.org/10.3390/cancers10040099.

40. Fukano R, Mori T, Kobayashi R, Mitsui T, Fujita N, Iwasaki F, et al. Haematopoietic stem cell transplantation for relapsed or refractory anaplastic large cell lymphoma: a study of children and adolescents in Japan. Br J Haematol. 2015;168:557-63.

41. Morel A, Briere J, Lamant L, Loschi M, Haioun C, Delarue R, et al. Long-term outcomes of adults with first-relapsed/refractory systemic anaplastic large-cell lymphoma in the pre-brentuximab vedotin era: A LYSA/SFGM-TC study. Eur J Cancer. 2017; 83:146-53.

42. Chan TS, Khong PL, Kwong YL. Pembrolizumab for relapsed anaplastic large cell lymphoma after allogeneic haematopoietic stem cell transplantation: efficacy and safety. Ann Hematol. 2016;95:1913-5.

43. Hebart H, Lang P, Woessmann W. Nivolumab for refractory anaplastic large cell lymphoma: a case report. Ann Intern Med. 2016;165:607-8.

44. Rigaud C, Abbou S, Minard-Colin V, Geoerger B, Scoazec JY, Vassal G, et al. Efficacy of nivolumab in a patient with systemic refractory ALK + anaplastic large cell lymphoma. Pediatr Blood Cancer. 2018;65. https://doi.org/10.1002/pbc.26902. 